\title{
A Defence of Intentionalism about Demonstratives
}

\begin{abstract}
Intentionalism about demonstratives is the view that the referent of a demonstrative is determined solely by the speaker's intentions. Intentionalists can disagree about the nature of these intentions, but are united in rejecting the relevance of other factors, such as the speaker's gestures, her gaze, and any facts about the addressee or the audience. In this paper, I formulate a particular version of this view, and I defend it against six objections, old and new.
\end{abstract}

\section{Intentionalism about Demonstratives}

Consider this scenario: at the dog park, I tell someone that my dog's name is 'Fido'. She asks: which one is Fido? I answer, pointing in the direction of my dog:

(1) This is Fido.

Assume that everything goes well and that my interlocutor now knows which dog is mine. The question I will address is this: in virtue of what does that use of 'this' refer to Fido?

This question is as interesting as any other question about the mechanism by which reference is secured. Additionally, demonstratives are interesting because they seem to rely on the speaker's intentions. This is in contrast to other types of expressions: 'today' picks out the current day, irrespective of the speaker's intentions. Whatever 'university' picks out - a property, a collection it does not do so in virtue of the speaker's intentions. I will defend one variant of intentionalism, namely the view that it is the speaker's intentions, and nothing else, that are at work in cases like (1): 
Expressive Intentionalism: the referent of a use of a demonstrative in a sentence is the referent of the corresponding demonstrative element of the thought that the speaker intends to express by that sentence.

For the rest of this section, I attempt to put more meat on these rather bare bones. I won't defend the view yet; for now, the goal is to spell it out a bit.

First, I only discuss paradigmatic demonstratives, like 'this' and 'she', and I ignore other expressions that are arguably demonstrative-like, such as possessives, modals, tense, and adjectives. I also intend the view to apply only to exophoric uses of demonstratives, i.e. uses whose referent is not fixed by the discourse. Furthermore, I focus on uses of demonstratives that stand for currently perceived objects in the speaker's environment. This is, admittedly, the best kind of case for the theory I propose. Many objections have been offered to these central cases, and my goal is to address those objections.

Second, this is more than a mere identity thesis. I claim that the referent of a use of a demonstrative is determined by the application of the thought-demonstrative to the world, combined with the speaker's intention to use the word in that way. The application yields a referent, whether or not the speaker or anyone else can figure out which object is the referent. This places the view squarely in one corner of a widely disputed area of disagreement, regarding the use of a non-epistemic notion of reference. By defending the view discussed here I hope to provide some support to the much broader view that such a notion is indeed useful.

To this I add just one caveat: demonstratives often have some restrictions associated with them, sometimes called 'phi-features'. 'She' is marked for gender; 'this' for proximity.Here, I remain neutral about the semantic import of these restrictions. At best, they can restrict what is available for reference, rather than determine the referent.

Third, the view is about the referent of a use of a demonstrative. I do not mean to choose between saying that an act refers ('a use'), that a speaker refers ('by using a demonstrative, the speaker referred'), or that an expression, when used, refers ('as used').I use these terms as seems most natural in the context. But I do want to avoid the notion of an occurrence of a demonstrative, 
proposed in Kaplan (1989b), which allows the semanticist to talk about the referent of an occurrence of a demonstrative relative to a context in which that demonstrative is not being used. To some extent, the choice is not important here: I focus on cases where the two views agree, namely ones in which the expression is being used with the right kind of intention. But the semanticist should not be allowed to posit referents when none are intuitively available. Consider a context in which someone says 'I am hungry'. Specify that context as minutely as you wish, and ask yourself: what is the referent of 'this' relative to that context? My intuition is that there is no referent here, because 'this' was not used, so the speaker intended nothing with respect to it.

Fourth, different versions of intentionalism have been widely discussed. The locus classicus of intentionalism is Kaplan (1989a, p. 582): the speaker's 'directing intentions' determine the referent of 'perceptual demonstratives'. ${ }^{1}$ Kaplan offered few details, but discussions have usually focused on versions of this view:

Referential Intentionalism: The value of a use of a demonstrative in a context is $o$ iff the speaker intends $o$ to be the value of the demonstrative in that context. ${ }^{2}$

Finally, I assume that there are demonstrative elements of thoughts. This is not a trivial assumption, but I will not defend it here. I only assume that people can think of particular objects in a context, in a way that essentially involves an exercise of that capacity in that particular context. Unofficially, I have found it useful to think along the model provided in Burge (2009). We start from thinking of thoughts as representations. These are finer grained than strict Russellian

\footnotetext{
${ }^{1}$ At the time, Kaplan was thinking about the intention that directs the hand that performs the demonstration, e.g. the hand that points to Fido (personal communication), though this is not made apparent in the text.

${ }^{2}$ This is quoted from Speaks (2016, p. 303); see also Siegel (2002) and King (2014, p. 221). Reimer (1992, pp. 383-384) calls the following 'the intentional view': 'the demonstratum of a demonstrative expression is determined entirely by the speaker's intention to demonstrate, and say something of, a particular object or individual'. A more widely expressed, but rarely elucidated, view is that the referent is determined by what the speaker had in mind. See Donnellan (1966); Burge (1974); Kripke (1977); Davies (1982); Lepore \& Ludwig (2000); Szabó (2006). For discussion of other ways to develop intentionalism, see Speaks (2017, §5.2).
} 
propositions, because one can have different singular representations of a single object. When I talk about 'expressing a thought', I mean something more than expressing a Russellian proposition: I mean that what is expressed is a representational entity, with elements such as thoughtdemonstratives. Putting aside many important details, Burge's picture starts from the primitive notion of an attributive, which is a particular way of representing an individual as having a certain property (Burge (2009, p. 253)). Singular elements in perceptually based representations are applications of attributives that are context-bound and individuated in terms of specific occurrences of those applications. ${ }^{3}$ Attributives are, according to this view, the kind of thing that, when applied in a context, gives rise to a representation of an object. The representation must be true of the object being represented, but only with respect to very low-level properties (e.g. being an object of a bounded shape, though the object's actual shape may differ from how the object is represented). ${ }^{4}$ This is not a descriptivist theory: the attributions that must fit the object are just those that spell out the conditions for the perceptual system to single out an object in the environment. Moreover, this kind of representation is not repeatable: it essentially involves an application in the specific context of that application (Burge (2009, p. 263)).

Burge's view invites the following question: in virtue of what does a thought-demonstrative refer to an object? Burge does not answer this question, and neither will I. The only assumption I need to make is that thought-demonstratives do not refer in virtue of linguistic facts. If I can answer a language question by assuming that there is an independent answer to a mind question, I think of that as progress, since we need the latter question answered anyway.

\footnotetext{
${ }^{3}$ I am paraphrasing from Burge (2009, 255-260).

${ }^{4}$ Burge (2009, p. 291).
} 


\section{Some Alleged Problems for Expressive Intentionalism}

Intentionalism is a simple view, and complicated cases have often been presented as counterexamples. ${ }^{5}$ On the whole, however, the impression was that intentionalism works well for easy cases like (1), ones in which a demonstrative is used to refer to an object that is currently perceived by both the speaker and the addressee. Recently, intentionalism has been accused of failing even in these easy cases. My aim in this paper is to address some of these objections.

\subsection{Psychological Plausibility}

Let us start with referential intentionalism, which, by avoiding talk of expressing thoughts, seems more psychologically benign. It requires the speaker to intend to refer to a particular object with a particular use of a demonstrative. Speaks (2016, pp. 304-305) objects that this is psychologically implausible, because it is unlikely that a young child, a competent user of demonstratives, would be able to form an intention that involves concepts of reference, tokenhood, uses, etc.

Is referential intentionalism guilty of over-intellectualization? Not necessarily. The view may be attributing intentions from above, from the theorist's point of view. The speaker is correctly described as intentionally using their vocal chords in ways that they could not describe, e.g. because they lack the capacity to form the right concepts. Similarly, a three-year old might have a mental state which can be described as an intention to refer, without requiring that she have any semantic concepts.

Much depends on the way that referential intentionalism is spelled out. Expressive intentionalism has a simple answer: it only requires the capacity to use thought-demonstratives, and the intention to express those thoughts (plus the knowledge that demonstratives are the right vehicle for carrying out this plan). This view does require that the child be able to think about expressing her thought; but this is in line with the generally accepted view that three year olds have a sufficiently developed theory of mind to do that (see Gundel et al. (2007); Gundel \& Johnson (2013),

\footnotetext{
${ }^{5}$ An early classic is the Carnap / Agnew attempted deferred reference case from Kaplan (1978, p. 239).
} 
and the many references therein).

In fact, the research is even more supportive of EI. According to Gundel \& Johnson (2013, p. 46), three year olds think about the components of others' mental states, and compare them to the respective components of their own mental states. For instance, in order to choose correctly between using 'it' and 'this', the child needs to figure out whether the referent is in the focus of the addressee's attention, or merely in working memory. If the latter is the case, Gundel argues that 'it' would be inappropriate. Furthermore, the child needs to ascertain whether their own representation of the referent is of the same kind as the representation in the mind of the addressee. This may seem overly demanding of children, or even of adults. But the claim is that this is not explicit thinking, nor is it available to introspection.

Admittedly, Gundel does not talk about thought-demonstratives in the Burgean sense. But the cognitive capacities that she does talk about are of the same kind as the ones that EI needs: a three year old can think about their own mental representations, and categorize them in certain ways, and thus can use them in communicative plans.

Finally, one could worry that I discuss only sentences containing one demonstrative. But the view is meant to generalize: given a thought involving several thought-demonstratives, each language-demonstrative gets its referent from the corresponding thought-demonstrative. The added feature is the correspondence. The speaker's intentions must then play two roles: the speaker must intend to express that thought, and must intend to match each language-demonstrative use to one thought-demonstrative. A reviewer asks if this raises new psychological plausibility problems. I do not think so. The child must intend to link each language-demonstrative to one thoughtdemonstrative. Here is the relevant part of the plan to express a two-demonstrative thought: I need two language-demonstratives, because the thought I want to express contains two thoughtdemonstratives, and each language-demonstrative is used to express the part of the thought contributed by the thought-demonstrative. But in order to make this plan, the child does not need the concepts THOUGHT-DEMONSTRATIVE, PART OF THOUGHT or REFERENCE. She just needs the ability to match demonstratives of one kind to demonstratives of the other in the right way, plus 
the relevant linguistic knowledge that language-demonstratives can be so used.

\subsection{The Problem of the Insufficient Demonstration}

Expressive intentionalism does not mention the audience, neither in terms of uptake, nor in terms of the speaker's communicative attitudes. Usually, the speaker strives to make clear to the audience what object she wanted to talk about. The speaker may, for instance, point at or otherwise demonstrate the object. But according to expressive intentionalism, this is all irrelevant as far as reference is concerned. In this, I follow Kaplan (1989a, p. 582): 'the demonstration [is] a mere externalization of [the directing intention]. The externalization is an aid to communication, like speaking more slowly and loudly, but is of no semantic significance'.

One kind of objection is based on cases that purportedly show that when the speaker does not do a good enough communicative job, she also fails to secure a referent for her uses of demonstratives. In these cases, a demonstration would be welcome, but either none is offered, or the one offered is insufficient. ${ }^{6}$ Here is the beach case from King (2014, p. 224):

I am sitting on Venice beach on a crowded holiday looking south, with swarms of people in sight. I fix my attention on a woman in the distance, and, intending to talk about her and gesturing vaguely to the south, say 'She is athletic'. It seems quite implausible in such a case to say that I succeeded in securing the woman in question as the value of my demonstrative simply because I was perceiving her, intending to talk about her and gesturing vaguely in her direction. ${ }^{7}$

Here is the challenge to expressive intentionalism: it predicts that 'she' refers to a particular person, which goes against King's intuition that reference fails. I share King's unease about the

\footnotetext{
${ }^{6}$ Speaks (2016, p. 305) calls this the problem of insufficient intentions. I changed the label because the cases tend to depend not on the speaker having insufficient intentions, but rather on poor externalizations of her intentions.

${ }^{7}$ Cases like this have been a staple in the literature; see, for instance, Reimer (1991a, pp. 194-195), and Gauker (2008, p. 363).
} 
case: something clearly went wrong. But my intuitions are not fine enough to trace the effect down to the reference level. I am inclined to believe that, just like any case, it is more likely to teach us something when placed within a broader philosophical picture. So before I address the beach case, I need to describe King's account of the semantics of demonstratives:

Coordination Account: the value of a demonstrative in a context is the object $o$ that meets the following two conditions: 1) the speaker intends $o$ to be the value; and 2) a competent, attentive, reasonable hearer would take $o$ to be the object that the speaker intends to be the value. (King (2014, p. 225))

The coordination account is thus referential intentionalism, plus the condition that the speaker do 'enough to allow her audience to recognize what she intends to be the value'. That condition comes from King's view that a semantic theory for demonstratives must characterize 'what must happen on the speaker's side in order for communication to succeed' (King (2014, p. 203)).

My response begins by considering a related account, which strengthens the second condition:

Successful Coordination Account: the value of a demonstrative in a context is that object $o$ that meets the following two conditions: 1) the speaker intends $o$ to be the value; and 2) the addressee takes $o$ to be the object that the speaker intends to be the value.

Both coordination accounts predict that 'she' fails to refer in the beach case: the addressee does not figure out whom the speaker intended to speak about, and the speaker did not do a good job making herself clear either to the actual audience, or to the ideal audience.

King (2014, p. 225) argues that the second condition in the successful coordination account is too strong, because the addressee's being 'inattentive, incompetent, or simply ignoring' the speaker should not prevent the demonstrative from referring.

I agree with King's claim that the addressee's uncooperativeness should not prevent reference success. But I would argue that King's view of semantics leads to the successful coordination account. So his criticism of the latter works against his own view. King would have us think 
of semantics as requiring the speaker to do what is reasonable for communication to succeed, given a reasonable addressee. But why not require that the speaker do what is actually needed, no matter how unreasonable that would be, given the actual addressee, no matter how unreasonable he might be? If the addressee is inattentive, the speaker should attempt to remedy that before saying something; if the goal is successful communication, then all such prerequisites become the business of the speaker.

King might reply that the cases he means to exclude are those in which the speaker is not communicationally blameworthy. Along with Speaks (2016, p. 327), I doubt that there is a good, clear way to separate these cases. But even if there is, if semantics is to tell us 'what must happen on the speaker's side in order for communication to succeed', then it is bound to tell us more than what would count as fair criticism of the speaker given a reasonable audience. I conclude that, on King's conception of semantics, the focus should be on the actual addressee, not the reasonable one.

There are independent reasons to reject the successful coordination account. As Speaks (2016, p. 327) notes, misunderstanding is always possible. But if we require successful communication for successful reference, there can be no misunderstanding with respect to the referent of demonstratives. So it is not a plausible account. But it shows that the beach case does not show that expressive intentionalism is false, since our intuitions are not clearly about the reference of demonstratives. The way to connect such cases to reference is through a view of semantics, or at least of reference, via a story that makes sense of intuitions, while also presenting a useful theoretical picture. King offered such a connection, but his proposal leads to an implausible account. So this way to make the connection fails. ${ }^{8}$

There may be other ways to make the connection between intuitions about the beach case and claims about reference. But I can offer two pre-emptive rejoinders.

First, note that expressive intentionalism has a simple story to tell here. The speaker did a bad

\footnotetext{
${ }^{8}$ For more discussion of the coordination account, which is more complex than my sketch, see King (2013b, 2014); Speaks $(2016,2017)$.
} 
communicational job, and the hearer could not figure out whom 'she' refers to. The speaker thus failed as a communicator, but not as a referrer: she had a demonstrative thought that picked out a particular person, and she used a language-demonstrative to refer to her. So she said something true. Her overall communicative intention required more: that the addressee be able to understand her. Our intuitions about the beach case track the speaker's failing this last requirement.

Second, here is a case in which both coordination accounts make the wrong predictions:

The absent-minded professor case: Julia is teaching a class on ontology. She is presenting her own view that objects made up of natural materials are more than mere collections of atoms. She is agnostic about objects made up of artificial materials, and, unless pressed, she prefers not to discuss them. She starts the class by announcing that she will defend the view that some medium-size objects are more than mere collections of atoms. To her right, among the clearly visible objects are a wooden chair, the only natural-material object in the room, and many other chairs, all obviously made of plastic. Vaguely pointing to her right, and giving little thought to the membership of her audience, she says 'That is more than the sum of its atoms'.

Julia is being a poor communicator, because her students have no way of knowing that she is referring to the wooden chair. But it seems to me that the demonstrative does refer to it, a fact that the students may come to realize, and that she could make clear if she wanted to. ${ }^{9}$

Putting those intuitions aside, consider a slight change: suppose the audience are all graduate students, all of whom know Julia's views. They would have no problem figuring out the referent of the demonstrative, so her communicative act succeeds. If asked, both she and the students would say that the wooden chair was the referent. But that is irrelevant while considering Julia's performance as a speaker: she is absent-minded, and in neither case does she pay enough attention

\footnotetext{
${ }^{9} \mathrm{I}$ said earlier that intuitions are not immediate guides to claims about reference. And yet I appeal here to my intuitions. I do not think I am contradicting my principles. Just like King, I support the relevance of my intuitions by presenting expressive intentionalism as a picture about demonstrative reference. Intuitions accompanied by a picture are not perfect guides either. But they are better than unaccompanied intuitions.
} 
to her audience. Because of this carelessness, she is a poor communicator to both audiences, in just the same way.

The absent-minded professor case shows that speakers may fail as communicators, and be blameworthy for it to extents that vary with the circumstances, without thus failing as referrers. Our intuitions do track speaker failures. But that tells us little about the referents of the demonstratives they use without a background story about reference and communication. ${ }^{10}$

\subsection{The Problem of Conflicting Intentions}

Referential intentionalism claims that, although speakers often have several intentions about the reference of a demonstrative, their referential intention trumps all others. Dissenters object that this view cannot explain why that happens.

In response to a query of 'Which dog is Fido?', the speaker comes out with an utterance of 'This is Fido'. As the speaker utters this, she opens her arms to embrace (and thereby demonstrate) the intended demonstratum - Fido. But Fido, suppose, suddenly zooms off in the opposite direction. And into the arms of the speaker rushes Spot - just as the former comes out with her utterance. Clearly the speaker's utterance was false, and was so on account of the fact that the speaker said falsely of Spot that he was Fido. ${ }^{11}$

Reimer (1991b) claimed that this case shows that referential intentionalism is false: it was the demonstration that determined the referent (Spot), not the speaker's intention to refer to Fido. Bach (1992, p. 143) argued that this kind of case does not prove that the referent was not intended by

\footnotetext{
${ }^{10}$ A similar point is made in Siegel (2002, p. 19), although Siegel is mainly claiming that our intuitions depend on the facts we posit about the audience, whereas I claim that our intuitions are not a precise guide to claims about reference.

${ }^{11}$ This is almost a quote from Reimer (1991b, p. 182), except that I changed 'this dog' to 'this', in order to stick to bare demonstratives, and I changed the gender of the speaker to match the earlier cases.
} 
the speaker, because she also intended to refer to the dog in her lap. So the problem is really one of conflicting intentions. ${ }^{12}$

All types of intentionalism have several ways to answer this challenge. The most promising appeals to the Bratman (1987) account of intentions as practical attitudes involved in planning for the future. ${ }^{13}$ The details must be filled out, but some applications are straightforward. The speaker intends to talk about Fido, and about the dog in her arms. The speaker's plan involves talking about the dog in her lap, since, given her belief that the dog in her lap is Fido, that will help her talk about Fido in a way that would be communicatively felicitous. The trumping intention would be the 'last one' in the plan, the one that is a means to fulfilling all other intentions.

As Speaks (2017, pp. 20-21) notes, this answer assumes that the plan is structured so that the result matches our intuitions about reference. But, to return to the Fido case, it could very well be that the speaker intends to talk about Fido only in order to talk about the dog in her lap. Suppose we change the case slightly, and she says 'play with this one!', where she has the intention to refer to the dog in her arms only because she believes that it is a Dalmatian, and her operational intention is to refer to some Dalmatian or other. This prediction goes against the intuition that the demonstrative refers to Spot, not to Fido, irrespective of the structure of the speaker's intentions.

Expressive intentionalism has little to say about the latter case, since it is restricted to uses of demonstratives for things currently perceived. I will come back to this issue in $\S 3$. But conflicting intentions problems can arise for it in a similar kind of case, with several demonstrative thoughts that are equally in the running. Here is such a case from Siegel (2002, pp. 10-11):

You are a salesman in a tie store. By reaching past an opaque door into a display case, you put your hand on a blue silk tie. At the same time, another salesman is reaching through the cabinet and touching a red silk tie. Through the glass top of the cabinet, you can see the red tie being held by the other salesman, whose arm looks like yours. You mistake his hand for yours and you believe that you are the one touching

\footnotetext{
${ }^{12}$ I owe the label to King (2014).

${ }^{13}$ King (2013b) discusses this answer.
} 
the red tie. You say to a customer, who was looking in another direction for a red silk tie, "This one is red."

Siegel's own theory predicts that 'this' refers to both ties. I doubt that a singular demonstrative can refer to two objects at the same time, or else the distinction between 'this' and 'these' becomes a mystery. She also considers a version of her theory predicting that reference fails. ${ }^{14}$ On this version, reference only happens when there is a unique object such that the speaker has a perceptually anchored intention to refer to it by her use of a demonstrative. The view appeals to an intention to refer, and thus falls prey to the same criticism as referential intentionalism. The uniqueness clause seems to me to give the right prediction, however. Can expressive intentionalism make the same prediction? The answer is not obvious, because the view only says that the referent depends on which thought the speaker intended to express. Here we have two good candidates for this role.

King's appeal to plans helps here. Consider three variations on the tie case. First, the customer is looking for a red tie (and does not care about the fabric); here, the visual demonstrative is the one most relevant to the salesman's plan. Second, the customer is looking for a silk tie (and does not care about the colour); here, the touch demonstrative is the one that matters. Third, in the original case, the touch and the visual demonstratives are equally relevant. Let us begin at the thought level: the speaker has a thought about the red tie, via a visual demonstrative, and another thought about the blue tie, via a touch demonstrative. She wrongly takes these thoughts to be of the same tie. Think about her plan: she thinks there is just one tie, that she both sees and touches; depending on both ways of thinking about the tie, she thinks about it. It is unclear to me how one should count the thoughts here: is it that she has just one inter-modal thought, or two for each perceptual system, or maybe even all these three? However it happens, her plan is grounded on a confusion at the level of thought, and thus the language-demonstrative she uses fails to refer to any tie.

Even if the reader does not share my intuitions about the tie case, talking about confusion here is the right way to go. ${ }^{15}$ Confusion creates all manner of problems, none of which are specific to

\footnotetext{
${ }^{14}$ See Siegel (2002, pp. 11-12).

${ }^{15} \mathrm{By}$ contrast, it would be wrong to talk about confusion in the Fido case. There, the speaker's plan was clear: pick
} 
demonstratives. So to the unconvinced reader I say: given a view about confusion, we can come back to this case and just apply that view.

\subsection{Humpty Dumpty}

Humpty Dumpty famously claims that he can make any word mean whatever he wants. ${ }^{16}$ To this, Alice replies that we cannot just impose upon our words whatever meaning we want. Michaelson (unpublished) presents this as a problem against referential intentionalism, but it works as an objection against any kind of intentionalism: how could the speaker's intentions have ultimate and unlimited power over the speaker's words?

Expressive intentionalism has a Humpty Dumptyesque flavour: demonstratives are said to express a certain kind of thought, with no concern for the addressee, salience, or anything else related to communication. There is no danger of wholesale Humpty Dumptyism, however, since expressive intentionalism is a very restricted view. Demonstratives form a closed class, so there is no danger of infecting the whole of language. The worst we can say about an otherwise orthodox expressive intentionalist is that she considers demonstratives a special kind of expression, one that, unlike nouns and verbs, is guided towards its referent solely by the speaker's mental states.

What would prevent an expressive intentionalist from going full Humpty Dumpty? One could be moved by the intuition that it is wrong to claim that 'glory' means 'a knock-down argument' and any explanation of the word's referent is unlikely to be solely about the speaker. When we focus on demonstratives, the first thing one says is either 'the thing the speaker is pointing at', or 'the thing that the speaker is thinking about', or some other such fact about the speaker. Expressive intentionalism chooses one of these facts about the speaker as determining reference.

A second Humpty Dumpty problem stems from cases where the speaker is demonstrating an

out the thing she perceives as being in her arms. Furthermore, she was not confused about that dog's being Fido at any point in the planning or in the execution of the plan.

${ }^{16}$ The literary reference is to Carroll (1871). The label as naming a philosophical problem comes from MacKay (1968). 
object without intending to refer to it. This will lead any reasonable addressee to believe that the demonstrative refers to the demonstrated object.

The bicycle case: I rap on the table in front of me, while intending to express a thought about my bicycle. I say 'This is a nice ride'. ${ }^{17}$

Suppose that the bicycle is within both the speaker's and the addressee's field of vision, but it is in no way made salient by the previous conversation, or by any of the speaker's actions. The addressee has no realistic way to figure out what the referent is, and she takes the speaker to be saying about the table that it is a nice ride. What matters for this case is the alleged intuition that the speaker did not manage to use a demonstrative to refer to her bicycle (we discuss whether the demonstrative refers to the table or to nothing at all in $\S 2.5)$.

My intuitions are not clear: I need to know whether the speaker has a comprehensible communication plan. Is she absent-minded, and thinks it obvious that the addressee can tell that she's talking about the bicycle? Then this is just like the absent-minded professor case, and reference is successful. Or, as Michaelson (2013, p. 59) wonders, does she have the false belief that she is addressing a mind-reader who immediately knows what her intentions are? Contra Michaelson, I do not find this far-fetched. We all are mind readers; it's just that this speaker would be unreasonably overestimating the addressee. She is criticizable for this, and for later trying defend herself in a trial by claiming that, although one would have naturally taken her to be talking about the table, she only intended to talk about the bicycle. Her defence would surely fail, since she is guilty of misleading her addressee. But that prove not that expressive intentionalism is wrong, but that the semantic fact is not the one that the trial rides on. ${ }^{18}$

\footnotetext{
${ }^{17}$ This is adapted from Michaelson (unpublished, fn. 23, p. 12). I should note that the case is presented as motivation for Michaelson's own 'neo-Strawsonian' view, which is referential intentionalism, plus the restriction that, whenever there is a demonstration, the demonstrative cannot refer to something outside the range of the demonstration.

${ }^{18}$ What if the speaker knew that the addressee would be misled, but instead of intending that result, simply did not care? I don't think the semantic facts would differ in any way.
} 
This discussion allows me to address the above-mentioned case of Carnap / Agnew, which, strictly speaking, does not fall under the scope of this paper, since the speaker is not perceiving any of the candidates for reference. Although it is a complicated case, there is a way to address it that is friendly to expressive intentionalism. In the original version, the speaker points at a photo and uses 'he' to refer to the person it depicts. This brings in additional worries about deferred reference that are independent of the semantics of demonstratives; they arise for other expressions too ('The ham sandwich is at table 7'). ${ }^{19}$ Let me focus on a simpler version: Kaplan is in a room where a photo of Carnap usually hangs on a wall. Not knowing that a prankster replaced it with one of Agnew, and while facing away from it, Kaplan points to it and says 'That is a photo of a great philosopher'

What does 'that' refer to here? Intuitions vary. King (2013b) believes that reference fails, because of the conflict between the speaker's intentions. In conversation, I have heard speakers prefer each of the other natural options: the photo of Carnap and the photo of Agnew. I am unclear about my intuitions, without knowing more about Kaplan's communicative plan.

What does expressive intentionalism predict? If Kaplan intends to express the memory-based thought, and the pointing is only for the sake of helping the audience, the case resembles the bicycle case, with the addition of memory. Admittedly, Kaplan is less criticizable, since his plan was reasonable. But he missed an important fact, which may thwart his communicative plan. If, however, his expressive intention is strongly bound with his communicative one, so that in his mind there is just one thought that he is trying to express, we are nearing a confusion case, and I start leaning in the direction of the no-reference intuition.

The only intuition problematic for expressive intentionalism is that 'that' refers to Agnew's photo. Just like in the bicycle case, I would resist it, assuming certain facts about Kaplan's plans. In this particular case, I think it unlikely that Kaplan intends to express a thought about whichever picture is up on the wall. If such a case existed, expressive intentionalism would need to be amended with an account of how language-demonstratives connect with thoughts of this semidescriptive kind. This task goes beyond the scope of this paper. But note that the resulting theory

\footnotetext{
${ }^{19}$ See Nunberg (1995).
} 
will not attribute to demonstratives two disconnected referential mechanisms. If the thought being expressed is about Agnew's picture because it is the thing pointed at, the speaker must be thinking of it in a thing-pointed-at way. The thought thus essentially involves an application in that context of some attributive: the speaker intends to express something about whatever they are pointing at in that moment, with that particular act of pointing.

\subsection{The Irrelevant Intention}

Next up is the most radically anti-intentionalist objection. ${ }^{20}$ The claim is that in cases like the following, the speaker's intentions are entirely irrelevant, because they get trumped by the demonstration:

[C]onsider a speaker who wants to refer to Ann, but her hand becomes suddenly stuck, and so, [while saying 'She is happy',] she accidentally points at Sue, or, indeed, anything in the general direction of her pointing gesture. Quite clearly, though, intuitively, it is Sue, not Ann, who is the referent of 'she'. (Stojnic et al. (2013, pp. 507-508))

This case is presented as motivating their view that the referent of a demonstrative is determined entirely by the linguistic context, where demonstrations are 'a grammaticized constituent of the speaker's utterance'. ${ }^{21}$ This, they think, explains why linguistic rules (which include demonstrations) always trump the speaker's intentions.

As we move away from agency, I worry that the proverbial ants on the beach that happen to form a shape that looks like 'this' would count as making an utterance, or that that 'word' would count as referring, if it also happens to be accompanied by a flock of birds whose shape looks like an arrow. As we move away from speech acts to ways things look, whether or not they are

\footnotetext{
${ }^{20}$ Stojnic et al. (2013) present this as a difficulty for intentionalism, not as a proof against it, because they think intentionalists can work their way around it. I will, indeed, try to do that.

${ }^{21}$ Stojnic et al. (2013, p. 505).
} 
expressions of agency, I begin to lose grip on the intuition that reference happens. If, on the other hand, we posit that the speaker is misleadingly pointing at a thing that she later wants to claim she was not referring to, we move back to a version of the bicycle case. I therefore find the case unstable.

But Stojnic et al. (2013, pp. 507-508) do not rely merely on intuitions about reference. They also offer four reasons for thinking that the 'pointing' trumps the intention:

(a) the audience can follow up with: 'So, you're saying that Sue is happy' and 'That's false: Sue isn't happy'

(b) the audience cannot felicitously follow up with 'So, you're saying that Ann is happy' or 'That's false: Ann isn't happy'

(c) the speaker cannot felicitously deny she said that Sue is happy

(d) the speaker cannot felicitously claim she said that Ann is happy

Let me begin with three reactions to these intuition-based arguments. Suppose the addressee says 'so, you're saying that Sue is happy'. The speaker, it seems to me, may correctly reply 'no, my hand misfired / mispointed / was taken over by an evil scientist'. Admittedly, Stojnic et al. may claim that the speaker is now focusing on what she meant to say, rather than what she ended up saying. But this is precisely the problem: these reports do not obviously track what is being said. We can all agree on what each party's thoughts are, and on the felicity of reports, while disagreeing on the semantics.

Second, suppose that the speaker is speaking to herself, and the audience is composed of bystanders towards whom the speaker has no communicative intentions. I then lose all intuition that there is anything important about the pointing. Suppose someone from the audience says 'that's false: Sue isn't happy'. Nevertheless, she may persist and say 'no, you misunderstood, I was referring to Ann'.

Third, in a move reminiscent of the one about the absent-minded professor, suppose that it is clear to everyone in the conversation that the speaker meant to talk about Ann, not Sue. All the 
reports above seem incorrect in this situation. At best, the speaker may be asked why she pointed at Sue. Reliance on the gesture seems crucial only when it actually serves to guide the audience towards (what expressive intentionalism would say is) the referent of the demonstrative.

These points may not be immediately persuasive. Battles of intuitions rarely have a clear winner. So let me offer a more systematic answer.

Expressive intentionalism can offer the following account. The speaker has a communicative intention, but the execution of that intention fails. She is not at fault, but by the end of the utterance she knows that her intention failed. So her overall plan fails. The intention to express her thought, which, according to expressive intentionalism, is the only referentially relevant one, is not the most important intention in that plan, as it is just a means to a communicative end.

So how do the speaker and the addressee react to the utterance, and what do they report? The speaker knows that her overall plan failed. The hearer takes the plan to be about Sue. So they both react to the overall communicative intention. Where does that leave the expressive intention? Either expressive intentionalism is correct, and the intention generates a referent, or not. If not, there are two options. First, one could argue that there is no need to talk about the intention to express a thought; I address this option in $§ 2.6$. Second, one could claim that reference is achieved through the pointing, not through the intention. This is the choice made by Stojnic et al..

Where does that leave us? Irrelevant intention cases do not give us a reason to reject expressive intentionalism. Stojnic et al. claim that intuitions push in their direction. My intuitions differ from theirs, especially if we think in more detail about the 'pointing' in the cases under discussion. Besides, expressing one's thought can happen when there is no plan to communicate, and in those cases there is no intuition of mis-referring. Furthermore, expressive intentionalism does have a way to account for intuitions about these cases. Thus, these cases do not suffice to argue against expressive intentionalism. 


\subsection{The Pragmatic Intention}

The final type of objection does not rest on particular cases. It acknowledges that the speaker's intentions are referentially determinative, but places that phenomenon within pragmatics, not semantics. $^{22}$

Bach offers two arguments against intentionalism. First, Bach (2012, pp. 167-168) argues that it conflates reference by a demonstrative with reference by a speaker using a demonstrative. The point is that the former is derivative from the latter, and that stipulating that a demonstrative refers just in case a speaker refers by using it is pointless, and trivializes intention-based semantics.

Intentionalists can grant most of this. Suppose that speaking of a used demonstrative as referring adds nothing to speaking of the user as referring. However, we might want to allow, as Bach does, that we can speak of other expressions as referring (his example is pure indexicals, i.e. context-sensitive words that do not depend for their reference on the speaker's intentions). Then we would want a theory, call it 'semantics', that deals only with expressions as referring, while also keeping track of the ways in which they come to refer. This theory can say that the sentence 'I am identical with him' (while pointing in the mirror) may sometimes be used to say something true, and sometimes to say something false. Fitting demonstratives in a theory that deals with other kinds of expressions yields good results, and seems to have no negative consequences, as far as this point is concerned.

The second, 'deeper' problem concerns the nature of the intention that intentionalism proposes as determining reference. ${ }^{23} \mathrm{Bach}(2012$, p. 168) begins with the observation that the speaker only has a communicative intention, whose success depends on using 'that' to get the addressee to focus

\footnotetext{
${ }^{22}$ Bach has argued for this view in many places, but the version in Bach (2012) contains the most direct objection against expressive intentionalism. See also King (2013a), where King is defending his own view, but many of his responses to Bach would also serve in defence of expressive intentionalism. I should also note that reactions against Kaplan's view that rely on a Gricean analysis of communicative intentions as reference-determinative appeared soon after the publication of Kaplan (1989b); see Berckmans (1990).

${ }^{23}$ See also Heck (2002).
} 
on the intended object. The second part is the claim that the addressee's job is only to figure out the communicative intention, and thus that the alleged referential intention would be inert anyway.

Intentionalists can grant all thisExpressive intentionalism does not rely on referential intentions. It does not matter for intentionalism that there be a separate intention of a certain kind, and even less that there be such an intention available to the speaker by introspection. There just has to be an intentional structure relating the referent with the demonstrative use.

These two problems do not threaten intentionalism for a similar reason: communication is not the only purpose of language. It is true that when speakers attempt to communicate, success depends on the realization of a communicative intention. This does not entail that there is no more to language use than that. Judgements of success track more than reference and truth. Once we take out the communication part of the plan, intentionalists claim that we are left with the speaker's intention that connects a demonstrative use to its referent.

\section{Instead of Conclusion: What About Those Other Uses?}

In this paper, I defended expressive intentionalism against objections that seek to defeat it on its home turf: cases where demonstratives refer to objects currently perceived by the speaker and the addressee. I gave little in the way of reasons for the view, focusing instead on responding to those challenges. After some brief remarks about the content of the view, I argued that it is psychologically plausible, and that it can account for cases in which there is an insufficient demonstration, and cases in which the speaker has conflicting intentions. I then argued that it does not force one into Humpty Dumptyism about language. This was followed by a discussion of the opposite view: that the speaker's intentions are irrelevant for demonstratives' mechanism of reference. Finally, I argued that this species of intentionalism belongs in semantics, not in pragmatics.

I find the view immediately plausible, and it is hard to argue for something when you so find it. I also feel the weight of the observation that demonstratives are used in other ways, and that it is not clear that the view can be extended to account for them, but that is the topic of further work. 
In this section, I attempt to give courage to fellow travellers, and to show that all hope need not be lost.

First, it has long been noted that demonstratives are used non-referentially. One can say, for instance 'Every dog loves his owner', and the pronoun does not refer to a particular person. Kaplan (1989b, p. 489) claimed that this is merely an occurrence of a homonym of the demonstrative 'he', and thus it cannot be an objection against a theory of demonstratives that it does not deal with bound uses.King (2001) argued for his theory partly on the basis of its ability to encompass both uses. Expressive intentionalism may appear to lean towards the ambiguity side in this debate. But it does not; it need not claim that all there is to referential uses of demonstratives is given by an analysis that has nothing in common with other uses, or that cannot be subsumed under a more general theory. The view only claims that referents of these uses are determined by a certain type of speaker's intention, and that can be true independently of views about other uses.

Second, there are many kinds of uses of demonstratives that refer to things that are not being currently perceived. The cases closest to the ones discussed here are about objects formerly perceived. Bare demonstratives are harder to use here, but this is a natural utterance: 'I remember that night when ...'. I find the hypothesis of Burge (2009) that there are demonstratives in memory compelling; if correct, it would be easy to extend the current theory to those uses.

More generally, one may worry that the theory and its defence are ad hoc, and that whatever plausibility it has may be lost when moving to other uses, or that it will at best be part of a disjunctive theory, with no story to tell about the connection between the disjuncts. This is not such a great problem: even if Expressive Intentionalism has nothing to say about other uses, I do not think the overall theory is bound to be disjunctive. Suppose that one proposes a more general theory, which claims that referential uses of demonstratives are devices for expressing singular thoughts that differ in some important ways from proper names (perhaps because those are different kinds of singular thoughts, or because demonstratives do not add requirements like proper names, e.g. that the referent be called so-and-so). Some will rely on concurrent perception. Others will rely on memory. But the theory will be unified. 
I cannot defend such a general theory here. But I can address a couple of immediate objections. One objection is that there seem to be cases of demonstratives referring to objects that the speaker is not in perceptual, or even causal, contact with, and thus, arguably, cannot have singular thoughts about. Suppose I win a contest, and to select the prize, I am blindfolded, walked into a warehouse I had never been in before, and about whose contents I know nothing. I am told to point in some direction or other. In order to get a prize, I must say 'Let that be my prize'. Suppose I manage to point at a car. Then there is a strong intuition that I referred to the car by my use of 'that'. According to the general theory I sketched, I would need to have a singular thought about the car if I am to succeed in referring to it. Can I be said to have a singular thought about an object I never perceptually encountered?

The Expressive Intentionalist has at least two options. First, and my favourite, would be to accept (and extend) the view of Jeshion (2010), according to which I can have singular thoughts of objects that are important in a particular kind of way to my cognitive life, even if I am not acquainted with them. The idea would be that the singularity of a thought depends not on the way the agent came to have the thought (e.g. by seeing it), but rather on the form of the thought, which is purely a matter of cognitive organization. Alternatively, one could admit that non-singular thoughts can also be expressed using demonstratives. So long as the cases I discuss above are ones of expressing a singular thought, the theory need not be extravagantly disjunctive.

Finally, even if the correct general theory is quite different from the one sketched above, it will still either agree with Expressive Intentionalism in the cases I address, or not. That is, either it will say that in these cases, reference is accomplished via an intention to express a particular kind of thought, or it will not. If the overall theory shows that this is not the case in those cases, that will be a result of the theory, not of my restriction to these cases, and hence it will show that either some of my responses fail, or that there is a better argument against Expressive Intentionalism than the ones I addressed.

In fact, this answer is available for all other kinds of uses of demonstratives: deferred uses ('he's not here', pointing at the chair that someone always occupies), uses for imperceptible objects ('that 
is my favourite equation'), etc. Whether ambiguity is the right answer, or instead there is a unifying theory that deals with all uses, Expressive Intentionalism may still be true in its own limited way.

\section{References}

Bach, K. (1992). Intentions and Demonstrations. Analysis, 52, 140-146.

Bach, K. (2012). Context Dependence. In M. García-Carpintero, \& M. Kölbel (Eds.) The Continuum Companion to Philosophy of Language, (pp. 153-184). London: Continuum.

Berckmans, P. (1990). Demonstrative Utterances. Philosophical Studies, 60(3), 281-295.

Bratman, M. (1987). Intention, Plans, and Practical Reasons. Cambridge, MA: Harvard University Press.

Burge, T. (1974). Demonstrative Constructions, Reference, and Truth. Journal of Philosophy, 71(7), 205-223.

Burge, T. (2009). Five Theses on De Re States and Attitudes. In J. Almog, \& P. Leonardi (Eds.) The Philosophy of David Kaplan, (pp. 246-316). Oxford University Press.

Carroll, L. (1871). Through the Looking Glass. London: Macmillan.

Davies, M. (1982). Individuation and the Semantics of Demonstratives. Journal of Philosophical Logic, 11, 287-310.

Donnellan, K. S. (1966). Reference and Definite Descriptions. The Philosophical Review, 75(3), 281-304.

Gauker, C. (2008). Zero Tolerance for Pragmatics. Synthese, 165, 359-371.

Gundel, J. K., \& Johnson, K. (2013). Children's Use of Referring Expressions in Spontaneous Discourse: Implications for Theory of Mind Development. Journal of Pragmatics, 56, 43-57. 
Gundel, J. K., Ntelitheos, D., \& Kowalsky, M. (2007). Children's Use of Referring Expressions: Some Implications for Theory of Mind. vol. 48 of ZAS Papers in Linguistics, (pp. 1-21).

Heck, J. R. G. (2002). Do Demonstratives Have Senses? Philosophers’ Imprint, 2(2).

Jeshion, R. (2010). Singular Thought: Acquaintance, Semantic Instrumentalism, and Cognitivism. In R. Jeshion (Ed.) New Essays on Singular Thought, (pp. 105-140). OUP.

Kaplan, D. (1978). Dthat. In P. French, T. Uehling, \& H. Wettstein (Eds.) Contemporary Perspectives in the Philosophy of Language, (pp. 383-400). Minneapolis: University of Minnesota Press.

Kaplan, D. (1989a). Afterthoughts. In J. Almog, J. Perry, \& H. Wettstein (Eds.) Themes from Kaplan, (pp. 565-614). Oxford: Oxford University Press.

Kaplan, D. (1989b). Demonstratives. In J. Almog, J. Perry, \& H. Wettstein (Eds.) Themes from Kaplan, (pp. 481-563). Oxford: Oxford University Press.

King, J. C. (2001). Complex Demonstratives. Cambridge, Mass.: MIT Press.

King, J. C. (2013a). Kent Bach on Speaker Intentions and Context. Croatian Journal of Philosophy, $38,161-168$.

King, J. C. (2013b). Supplementives, the Coordination Account, and Conflicting Intentions. Philosophical Perspectives, 27, 288-311.

King, J. C. (2014). Speaker Intentions in Context. Nô̂s, 48(2), 219-237.

Kripke, S. (1977). Speaker's Reference and Semantic Reference. Midwest Studies in Philosophy, $2,255-276$.

Lepore, E., \& Ludwig, K. (2000). The Semantics and Pragmatics of Complex Demonstratives. Mind, 109, 199-240. 
MacKay, A. (1968). Mr. Donnellan and Humpty Dumpty on Referring. Philosophical Review, 77(2), 197-202.

Michaelson, E. (2013). This and That: A Theory of Reference for Names, Demonstratives, and Things in Between. Ph.D. thesis, University of California, Los Angeles.

Michaelson, E. (unpublished). Speaker's Reference, Semantic Reference, Sneaky Reference. December 24, 2015 draft.

Nunberg, G. (1995). Transfers of Meaning. Journal of Pragmatics, 12, 109-132.

Reimer, M. (1991a). Demonstratives, Demonstrations, and Demonstrata. Philosophical Studies, 63(2), 187-202.

Reimer, M. (1991b). Do Demonstratives Have Semantic Significance? Analysis, 51(4), 177-183.

Reimer, M. (1992). Three Views of Demonstrative Reference. Synthese, 93(3), 373-402.

Siegel, S. (2002). The Role of Perception in Demonstrative Reference. Philosophers' Imprint, 2(1), 1-21.

Speaks, J. (2016). The Role of Speaker and Hearer in the Character of Demonstratives. Mind, 125(498), 301-339.

Speaks, J. (2017). A Puzzle about Demonstratives and Semantic Competence. Philosophical Studies, 174, 709-734.

Stojnic, U., Stone, M., \& Lepore, E. (2013). Deixis (Even without Pointing). Philosophical Perspectives, 27, 502-525.

Szabó, Z. (2006). The Distinction Between Semantics and Pragmatics. In E. Lepore, \& B. Smith (Eds.) The Oxford Hanbook of Philosophy of Language, (pp. 361-390). Oxford University Press. 